\title{
The Stability-Standard of Sea-going Ships
}

\author{
By Yoshihiro Watanabe,* Kögakuhakushi, Member, \\ Naoto Yamagami,+ Kōgakushi, Member, \\ Shösuke Inone,\# Kögakuhakushi, Member \\ and Daikaku Manabe,"H Kögakushi, Member.
}

\section{General remarks}

When we calculate the ship's longitudinal strength, her strength is judged by the standard calculation not expressing the real ship's strength but the relative strength. On the contrary there is no definite stability standard in spite of many proposals and her stability is decided only by the designer's judgement. As it is the same with stability as with longitudinal strength, the exact analysis of ship's motion among irregular waves with wind and other external forces is almost impossible. The procedures which we shall adopt, are to examine the stabilities of sunken ships and of ships navigating safely for the past many years up to the present by the known and reasonable theories, to draw a boundary line between them, and to decide the stability standard.

But, it is necessary that its calculation is simple, its accuracy holds balance, and its calculation can be done by the drawings which are prepared at dockyards usually.

The good or bad qualities of ships' stabilities in smooth water may be determined by metacentric height GM, and in rough water GM, maximum righting arm $G Z_{\max }$ and stability range $\theta_{r}$ are main stability elements. If $\theta_{r}$ is included in dynamical stability, we may also admit, as main stability elements,GM, GZmax and dynamical stability. Bnt when we make the ship's stability the first object and make the other performance such as ralling the second object, GZmax and dynamical stability become main elements. So our researches are concentrated upon them as the elements to judge the stability.

Past researches on the stability standard may be divided into 2 groups, according to their methods, a statistical and a theoretical group, and we may refer here the following 5 papers.

Statistical group :

J. Rahola : The judging of the stability of ships and the determination of minimum amount of stability. 1939.

Y. Watanabe : The method of determining the ship's dimensions to adapt to the minimum requirement for her transverse stability (Journal of the society of naval architects of Japan 69 1941)

Theoretical group :

E. Pierrottet : A standard of stability for ships (TINA 1935)

Y. Watanabe : Safety criterion of a ship considered from the stability. (Journal of the society of naval architects of Japan 79 1948)

H. Kato : On stability qualities of small sea-going vessels (Journal of the society of naval architects of Japan 83 1951)

\footnotetext{
*\# Prof. of Kyūshū University.

+ Inspector of Kyūshū Marine Transportation Office.

Ht Assist. Prof. of Kyūshū University.
} 
But in the statistical method the given data of sunken ships are almost the cases in European sea, and there will be cases in which they are unfit for Japanese waters. And it is difficult to

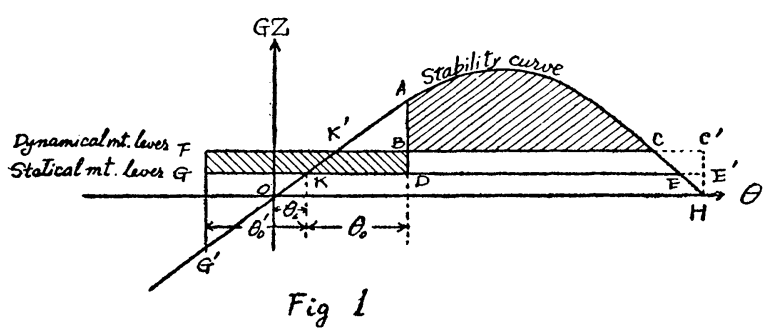
improve the standard of the ship's stability from the results introduced by statistical method, as the properties of each ship are not taken into account. Also, the question arises whether results introduced from a few ships' data may be applied to the different kinds of ships or not. "We shall, therefore reject the

statistical method and adopt the theoretical one.

The principles of theoretical method we take are as follows :

in Fig. 1 we consider that the ship heels to $\theta_{s}$ by statical couples (mainly, by steady wind pressure), rolls to $\theta_{0}$ and $\theta_{0}{ }^{\prime}$ on port and starboard sides successivelly, and, when she heels to $\theta_{0}{ }^{\prime}$, suffer dynamical couples applied suddenly (mainly du to gust of wind). In that case, the condition, that the ship doesn't capsize, will be

$$
\text { area } \mathrm{ABC}>\text { area } \mathrm{BFGD} \text {. }
$$

Add the area AOHCBA to being added to both sides, the left side becomes the dynamical stability $\operatorname{arm} S_{d}$ at $\theta_{r}$. So

$$
\begin{aligned}
& S_{d}>\text { area } \mathrm{BFGD}+\text { area } \mathrm{AOHCBA} \\
& S_{a}>\text { area } \mathrm{FCEG}+\text { area } \mathrm{OKEH}+\text { area } \mathrm{AKD}
\end{aligned}
$$

If statical couple lever $D_{w}$ and dynamical couple lever $D_{w}^{\prime}$ are assumed to be independent of heeling angle $\theta$ as usually taken,

$$
\begin{aligned}
& S_{d}>D_{w}\left(\theta_{r}+\theta_{0}^{\prime}\right)+D_{w} \theta_{r}+s_{w}-D_{w}^{\prime} \theta_{s} \text {-area } \mathrm{HECC}^{\prime}-\frac{1}{2} \theta_{s} D_{w} \\
& \text { where } s_{w}=\text { area AKD. }
\end{aligned}
$$

The left side of (1.2) is the reserve of stability of a ship to resist against external capsizing couples and the right side is the work done of external forces. Now the idea like "factor of safety" of elasticity be introduced, and we shall define, as "the stability-criterion," the ratio $C$ of $S_{d}$ and work done of external couple, that is

$$
C=\frac{S_{d}}{D_{w}{ }^{\prime}\left(\theta_{r}+\theta_{0}^{\prime}\right)+D_{w} \theta_{r}+s_{w}}
$$

The critical value of $C$ which is allowed for ship should be determined by considering the type of ships and sea-routes, and by calculating $C$ about these ships. It is quite empirical. From (1.2)

$$
\frac{S_{a}}{D_{w^{\prime}}\left(\theta_{r}+\theta_{0}^{\prime}\right)+D_{w} \theta_{r}+s_{w}}+\frac{\left.m_{w}\left(D_{w}+D_{w^{\prime}}\right)+1 \cdot \frac{1}{2}-D_{w}+D_{w}\right)^{2}}{D_{w}\left(\theta_{r}+\theta_{0^{\prime}}\right)+D_{w} \theta_{r}+s_{w}}>1
$$

where $m_{x}=\mathrm{GM}$ and $n_{x}$ is the slope of the stability curve at $\theta_{r}$,

And it follows $C>1$, but we do not consider that $C$ should be $>1$, by the reasons as will be explained latey.

Now, when $\theta_{c} \fallingdotseq \theta_{0}^{\prime}, \quad D_{w} \fallingdotseq D_{w}{ }^{*}$ and $s_{w}=\frac{1}{2}-m_{x} \theta_{0}{ }^{2}, \quad(1.3)$ becomes

$$
C_{w} \equiv \underset{D_{w}\left(2 \theta_{r}+\theta_{0}\right)+-\frac{1}{2} \cdot m_{x} \theta_{0}^{2}}{S_{d}}
$$

which is an expression** obtained by one of the authors.

* It is the case that $D_{w}$ and $D_{w}$ show wind moment only and the fluctuation of wind velocity is 40 percent of steady wind velosity.

** Y. Watanabe : Journal of the society of naval architects of Japan 79, 1948 
Also, by the addition of any area (Fig. 1) to both sides of (1.1) or the subtraction, new stability criterions can be obtained. For example, from (1.1)

$$
\begin{aligned}
& \text { area } \mathrm{ABC}+\text { area } \mathrm{ABK}^{\prime}>\text { area } \mathrm{BFGD}+\text { area } \mathrm{ABK}^{\prime} \\
& \text { area } \mathrm{CAK}^{\prime}>\text { area } \mathrm{FK}^{\prime} \mathrm{KG}+\text { area } \mathrm{AKD}^{\prime} \text {. }
\end{aligned}
$$

But area $\mathrm{AKD}=$ area $\mathrm{KGG}^{\prime}$, so

$$
\text { area } \mathrm{CAK}^{\prime}>\text { area } \mathrm{K}^{\prime} \mathrm{FG}^{\prime} \text {. }
$$

Then, $C_{K} \equiv$ area $\mathrm{CAK}^{\prime}$ /area $\mathrm{K}^{\prime} \mathrm{FG}^{\prime}$ is also a new stability criterion that is. Kato's expression. If. $D_{w}, D_{w}^{\prime}$ are independent of $\theta$ that expression becomes

$$
C_{K^{\prime}} \equiv \frac{S_{d}-\left(D_{w}+D_{w}\right) \theta_{r}+\left(\begin{array}{c}
D_{w}+D_{w^{\prime}} \\
2
\end{array}\right)^{2}\left(\begin{array}{c}
1 \\
m_{x}+\frac{1}{n_{x}}
\end{array}\right)}{s_{w}+D_{w} \theta_{0}{ }^{\prime}+\frac{D_{w^{\prime 2}}}{2}-\frac{1}{m_{x}}}
$$

And when the 3 rd terms of numerator and denominator, are neglected,

$$
C_{K^{\prime}} \equiv \frac{S_{a}-\left(D_{w}+D_{w^{\prime}}\right) \theta_{r}}{s_{w}+D_{w^{\prime}} \theta_{0^{\prime}}}
$$

\begin{tabular}{|c|c|c|c|}
\hline & Watanabe & Kato & Pierrottet \\
\hline $\begin{array}{l}D_{w} \text { at upright } \\
\text { condition }\end{array}$ & $0.76 \times 10^{-4}-\frac{\mathrm{Ah}}{\mathrm{W}} U^{2}$ & $0.78 \times 10^{-4}=\frac{\mathrm{Ah}}{\mathrm{W}}(q U)^{2}$ & \multirow{2}{*}{$0.1 \times 10^{-3-3 h}(40)^{2}$} \\
\hline $\begin{array}{l}\text { Fluctuation of } \\
\text { gust }\end{array}$ & $40 \%$ & $25 \%$ & \\
\hline $\begin{array}{l}D_{w}, D_{w}^{\prime} \text { when } \\
\text { heels }\end{array}$ & $\begin{array}{l}\text { The value at up-right } \\
\text { condition }\end{array}$ & $A, h$ at each heel angle & $\begin{array}{l}\text { The value at up-right } \\
\text { condition }\end{array}$ \\
\hline$U$ & $\begin{array}{l}\text { determined by the wave } \\
\text { length at worst condition }\end{array}$ & $\begin{array}{l}25 \mathrm{~m} / \mathrm{sec} \text { above } W=900 \text { ton, dec- } \\
\text { rease linearly under } W=900 \text { ton }\end{array}$ & $U=40 \mathrm{~m} / \mathrm{sec}$ \\
\hline$\theta_{0}$ & $\begin{array}{l}\text { synchronous rolling } \\
\text { angle }\end{array}$ & $\begin{array}{l}\text { synchronous rolling angle consi- } \\
\text { dering pseudo-harmonic effect }\end{array}$ & $\begin{array}{l}\text { determined by free-roll- } \\
\text { ing period }\end{array}$ \\
\hline $\begin{array}{l}\text { Dynamical } \\
\text { stability }\end{array}$ & at $\theta r$ & at $55^{\circ}$ & at $50^{\circ}$ \\
\hline where & \multicolumn{3}{|c|}{ 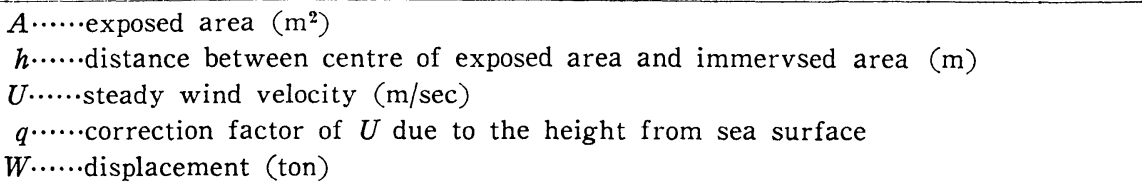 } \\
\hline
\end{tabular}

Other examples are as follows:-

$$
\begin{aligned}
& \frac{S_{d}-\left(D_{w}+D_{w^{\prime}}\right) \theta_{r}-\frac{m_{z}}{2} \theta_{0}^{2}+D_{w^{\prime}} \theta_{0}}{2 D_{w^{\prime} \theta_{0}}} \\
& S_{d}-\frac{1}{2} m_{x} \theta_{0}^{2} \\
& {\overline{D_{w}}}^{\prime} \theta_{0}+\left(\overline{D_{w}}+\overline{D_{w}}{ }^{\prime}\right) \theta_{r} \\
& \frac{S_{d}-\left(D_{w}+D_{w_{s}^{\prime}}\right) \theta_{r}+D_{w^{\prime}} \theta_{0}}{2 D_{w^{\prime}} \theta_{0}+\frac{1}{2} m_{x} \theta_{0}^{2}} \\
& \frac{S_{a}-D_{w^{\prime}} \theta_{0}}{\left(D_{w}+D_{w}\right) \theta_{r}+\frac{1}{2} m_{s} \theta_{0}^{2}} \\
& S_{d}-\frac{1}{2} m_{x} \theta_{3}{ }^{2}+D_{w}{ }^{\prime} \theta_{0} \\
& 2 D_{w^{\prime}} \theta_{0}+\left(D_{w}+D_{w^{\prime}}\right) \theta_{r}
\end{aligned}
$$

But if larger area be added to (1.1), stability criterion $C$ approaches to 1 and will tend to miss the meaning of stability standard. The next table shows the comparisons of some of theese methods. 


\section{The stabliity-standard}

\section{§ 1. External couples, to be considered.}

The ship's stability depends upon the relation between GM, GZ $Z_{\max }$, dynamical stability and external couples. Now, we may examine the external couples.

The external couples which have eflects on the ship's stability, are, caused mainly by following items,

(1) wind pressure (steady wind and gust)

(2) waves

(3) steering

(4) movement of passengers

(5) the shipping of sea water

(6) movement of cargo due to the ship's heel etc.

But it is common to neglect (4) in the case of seagoing ships. (5) has unfavourable effects statically and dynamically due to slow drainage on the weather deck even if water doesn't flood into watertight subdivision parts, but it is better that we leave it in reserve of so-called stability criterion because of the difficulty of its exact solution. As the effects of the movement of cargoes at large heel, can be included in thè stability curve, the external couples to be considered are (1) (2) (3). Among them, we think (1) and (2) as most important and the steering effect (3) is not considered, for that effect scarcely amounts to $20 \%$, while, on the other hand, the efiect of the drop of wind velocity due to the boundary layer induced by the sea surface is not taken into account, and these two effects have the properties to cancel each other. After all the external couples to be considered are (1) and (2).

\section{§ 2. The kinds of ocean wind}

As above-mentioned, the important external couples are raised by wind and waves and, as waves are generated by wind, it is necessary to consider about wind at first.

By the type of blowing, wind is divided into 2 kinds. The one is the wind almost blowing at constant velocity for long duration and the other is the gale blowing for short duration.

By the types of appearance it may be classified as

(1) prevailing wind

(2) fronts

(3) lows

(4) typhoons.

In the cases of (1) (2) constant wind blows for long duration (Fig. 2, 3, 4) and (3) (4) are the cases in which gale blows over central region for short duration, then turns the direction and soon becomes constant wind. (Fig. 2,3,4). Constant wind of (1) (2) (3) (4) is important for waves, because the wind blowing over sea in one direction for long duration is needed for the generation of large waves. (full explanations on this problem are given in our separate paper of this volume.) Of course in the central region of storm (the case of lows and typhoons in which the gale blows for short duration) waves are generated, but, because of the wind of short duration waves being irregular about size and direction and wind being very strong the central region of storm, the strong wind pressure has to be considered as a first order compared with irregular waves. It will also be thinkable from the log-book of meteorological observation ship "No.4 Kaiyo-maru" (she entered into the central region of typhoon indicated $904 \mathrm{mb}$, and escaped out of danger safely) in which the captain emphasized that the ship heeled at large angle due to wind pressure and drifted. So, we shall consider both the effects of wind and waves as the 
waves grow enough when constant wind blows for long duration and near the central region of the storm, the effect of wind only.

Then, the stability critenions in the theoretical method have to be classified in 2 kinds.

\section{$\S 3$. Stability criterions}

The stability criterions are the numbers showing the standard whether the ship is safe or not. This values are determnied empirically by data of sunken ships and the ships navgating safely. As this stability standard we use the stability criterion (1.3)

$$
C_{1}=\frac{S_{d}}{D_{w}\left(\theta_{r}+\theta_{0}^{\prime}\right)+D_{w} \theta_{r}+s_{w}}
$$

for it is more convenient when stability standard in the central region of storm is considered. (2.1) corresponds to the case in which both effects of wind and waves are considered, and another stabilty criterion $C_{2}$, in the central region of storm in which the wind pressure only be considered, is determined by putting $s_{w} \fallingdotseq 0$ and $\theta_{0}^{\prime}=0$ in (2.1). Then,

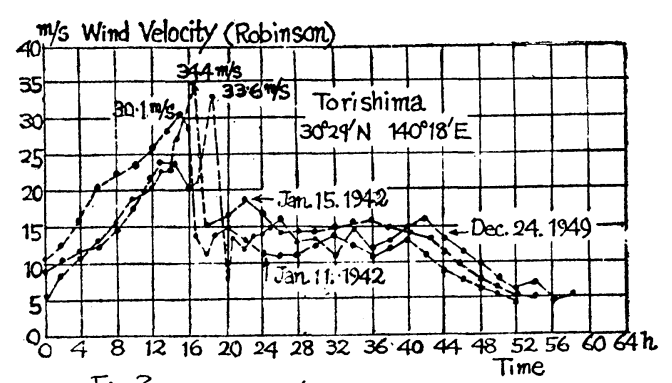

$$
\text { Fig. } 2
$$
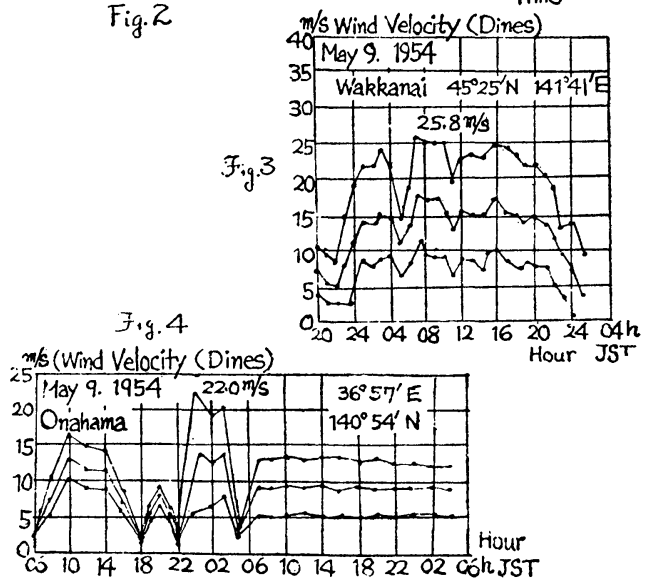

$$
C_{2}=\frac{S_{d}}{\left(D_{w}+D_{w^{\prime}}\right) \theta_{r}}
$$

$C_{1}$ and $C_{2}$ are necessary to be greater than some critical value in order that sea-going ships may voyage safely. In (2.1) (2.2) $D_{w^{\prime}}$ expresses the gust moment divided by the displacement in which values of fluctuation of wind and lever of moment contained in $D_{w}$ are important. Fluctuation is found to be $40 \%$ in the steady wind region of typhoons and $25 \%$ in the steady wind region of fronts and lows by the observation of ocean wind. But near islands and sea-side, the latter becomes $40 \%$ due to the effect of topography, and we therefore take $40 \%$ for fluctuation of all kinds of wind. The lever of moment is not always the distance between centres of exposed area and immersed area, but suffers from the effect of unsteady drifting. But in this criterion we follow the usual custom and take the same as the steady wind moment lever. Then, if in (2.1) $D_{w} \doteqdot D_{w^{\prime}}, \quad s_{w} \doteqdot{ }_{2}^{m_{x}} \theta_{0}^{2}$ and $\theta_{0} \doteqdot \theta_{0}^{\prime}$,

$$
C_{1}=\frac{S_{d}}{D_{w}\left(2 \theta_{r}+\theta_{0}\right)+\frac{m_{x}}{2} \theta_{0}^{2}}
$$

Also, in (2.2), if we put $S_{d}$, adopting a coefficient $\eta$

$$
\begin{aligned}
& S_{d} \fallingdotseq \frac{\eta}{2} \mathrm{G} Z_{\max } \theta_{r}, \\
& D_{w}+D_{w}{ }^{\prime}=\lambda U^{2}{ }_{\max }
\end{aligned}
$$

where $U_{\max }$ shows the maximum wind velocity and $\lambda$ is a constant,

(2.2) can be rewritten as

$$
C_{2}=\frac{\eta}{2} \frac{\mathrm{G} Z_{\max }}{\lambda U^{2} \max }
$$

Namely, by $C_{1}$ we can understand the dynamical stability as a factor of stability elements and by $\boldsymbol{C}_{2} \mathrm{GZ}_{\max }$ as another. 


\section{$\S 4$. Subjects concerning the calculations of the stability criterions}

(1) Stability curve :- -

The stability curves of the worst condition, which ships meet must be used and according to the results investigated up to the present it was found that the worst conditions are to be full load and consumed conditions and rarely ballast conditions.

The portions included in stability calculation are main body under the upper deck and weathertight forecastles, bridges and poops as usual. Then, we shall use them in this calculations. Also, it is questionable whether we may take the dynamical stability to $\theta_{r}$ or stop the calculation at a certain heeling angle $\theta_{i n}$ as Pierrottet and Kato. But in our case we shall take the former idea for it will be convenient to consider $\theta_{m}$ if the dynamical stability can be calculated by the approximate formula and, even if we stop the dynamical stability calculation at $\theta_{n}=50^{\circ} \sim 60^{\circ}$, the rest beyond $\theta_{m}$ is canceled by the wind moment and included in the allowance of stability criterions $C_{1}, C_{2}$ as $\theta_{r}$ of the merchant ship at the worst condition is smaller than $70^{\circ}$ generally. Of course in the case of warships, $\theta_{r}$ is larger, but the movements of cargoes are smaller than in the case of merchant ships and watertightness is better, so $\theta_{m b}$ shonld be taken larger than the merchant ship's $\theta_{m}$. Then from the same reason as the case of merchant ships, the limit of the dynamical stability of warships may also be taken as $\theta_{r}$.

Fig. 5 shows the relation of $\eta$ in (2.4) and $\theta_{r}$. From this the mean value of $\eta$ is about 1.22.

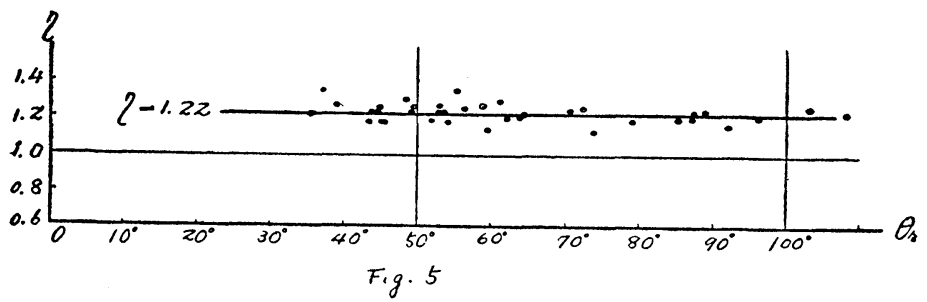

(2) Direction of wind and wave relative to the ship :- -

It is common to steer the ship to avoid the abreast wind and waves, but among shipwrecks there are many sunken ships which met with side wind and waves by the accidental loss of steering ability. It is very difficult in storm to expose the bow to the wind and, even if she has sufficiently powerful engines and steering apparatuses, she often meets with side wind and waves. So from the view point of the safety of ships it will be better to consider the ship condition with side wind and waves.

(3) Wind and waves :- -

For the calculations of wind moment and rolling angle, wind velocity and size of waves must be dtermined. In the past the relations between wind velocity, wave length and wave steepness were determined by the observation data, and in the method presented by one the authors, the most dangerous wind velocity, wave length and wave steepness were determined, and in Kato's method they were determined by the size of ships. Recently the theories of wind and waves have made great progress, and the relations* between wind and waves with fetch and duration, being given the wave steepness is also determined as a function of wave age. The typical values are as follows :

\begin{tabular}{c|c||c|c}
\hline wave age & wave steepness & wrve age & wave steepness \\
\hline 0.4 & $1 / 10$ & 0.85 & $1 / 20$ \\
0.62 & $1 / 13$ & 1.12 & $1 / 30$ \\
0.7 & $1 / 15$ & 1.4 & $1 / 40$ \\
\hline \multicolumn{2}{r|}{ wave age $=V_{w} / U$}
\end{tabular}


With this relation, if wave steepness is assumed, wave age and consequently wind velocity are determined for given wave velocity or wave period.

(4) Wind moment and rolling angle :-

Commonly the worst condition in the stand point of stability is that the ship meets with side wind and waves and synchronizes with waves. Wind moment in this case can be calculated by

nameiy in (2.4)

$$
0.76 \times 10^{-4} \mathrm{AhU}^{2}
$$

$$
\lambda=0.76 \times 10^{-4} \mathrm{Ah} / \mathrm{W}
$$

and independent of heeling angle. The rolling angle, when synchronism occurs is

$$
\theta_{0}=\sqrt{\frac{\pi \gamma \Theta_{w}}{2 N}}
$$

where $\gamma$ is effective wave slope coefficient,

$\Theta_{w}$ is maximum wave slope and

$N$ is extinction coefficient when resistance is proportional to the square

of angular velocity.

In this formula, $\gamma$ can be calculated by the method given by one of the authors.** Generally, as $N$ increases when the ship sails, $N$ at rest is on the safe side in the calculation of $\theta_{0}$. As in the storm the speed of the ship drops and also there is the case of no speed, we shall take $N$ at rest. $N$ may be obtained by model experiments or it is quite desirable that it can be calculated according to the size of ships and bilge keels etc.

\section{§ 5. Calculations of $C_{1}, C_{2}$}

$C_{1}$ can be calculated with (2.3) as follows :-

(1) Determine the ship's free rolling period $T_{\boldsymbol{s}}$ by the experiments or calculations.

(2) As the ship meets with side wind and waves and synchronizes, wave length $L_{w}$ is

$$
L_{20}=-\frac{g}{2 \pi} T_{8}^{2}
$$

or wave velocity $V_{w}$ is

$$
V_{w}=-\frac{g}{2 \pi} T_{s}
$$

(3) Assume the steepness and from $\S 4$ (3) determine wave age $V_{w} / U$. Then $U$ can be got.

(4) With (2.5) and (2.6) we can calculate $C_{1}$ as a function of $U . C_{2}$ can be calculated immediately by (2.3) with the assumed values of $U_{\text {max }}$.

\section{§ 6. The iudging standard of stability}

By the above mentioned process we calculated $C_{1}$ and $C_{2}$ of many ships and considered the allowable critical values of $C_{1}$ and $C_{2}$.

In this calculation the ships were classed in 2 groups. The one is the ships of the coasting route which navigate near the land and can take shelter in ports by warnings. Their values of $C_{1}$ and $C_{2}$ are showed in Fig. 6, 7. The other is the ships of coastwise and overseas route which navigate far from the land and cannot take shelter in ports by warnings. Their values of $C_{1}$ and $C_{2}$ are showed in Fig. 8,9. The ships which can not be classed in either of these groups are calculated about both cases.

* Bretschneider: The Generation and Decay of Wind Waves in Deep Water. Trans. A. Geophysical U. V. 33 June 1952

H. U. Sverdrup \& W.H. Munk : Wind, Sea and Swell : Theory of Relations for Forecasting. H. O. Pub. No. 601

Techniques for Forecasting Wind Waves and Swell. H.O. Pub. No. 604

** Y. Watanabe : Some Contributions to the Theory of Rolling. TINA 1938 
If tne curves of Fig. 6, 7, 8, 9 exist on the upper part of the figures the stabilities are better. When wind velocity decreases, $C_{1}$ and $C_{2}$ increase beyond the theoretical value 1 , and the upper limit of wind velocity can be determined for $C_{1}$ and $C_{2}=1$. But following conditions should be taken into considerations. If there are external couples not considered in calculation, they may become more than 1, and if the external couples be overestimated, for example the neglect of the boundary layer effect of wind velocity and gust moment, it is more proper to take smaller values than 1 . As to the boundary layer effect of wind velocity, the wind velocity of the meteorological observatory
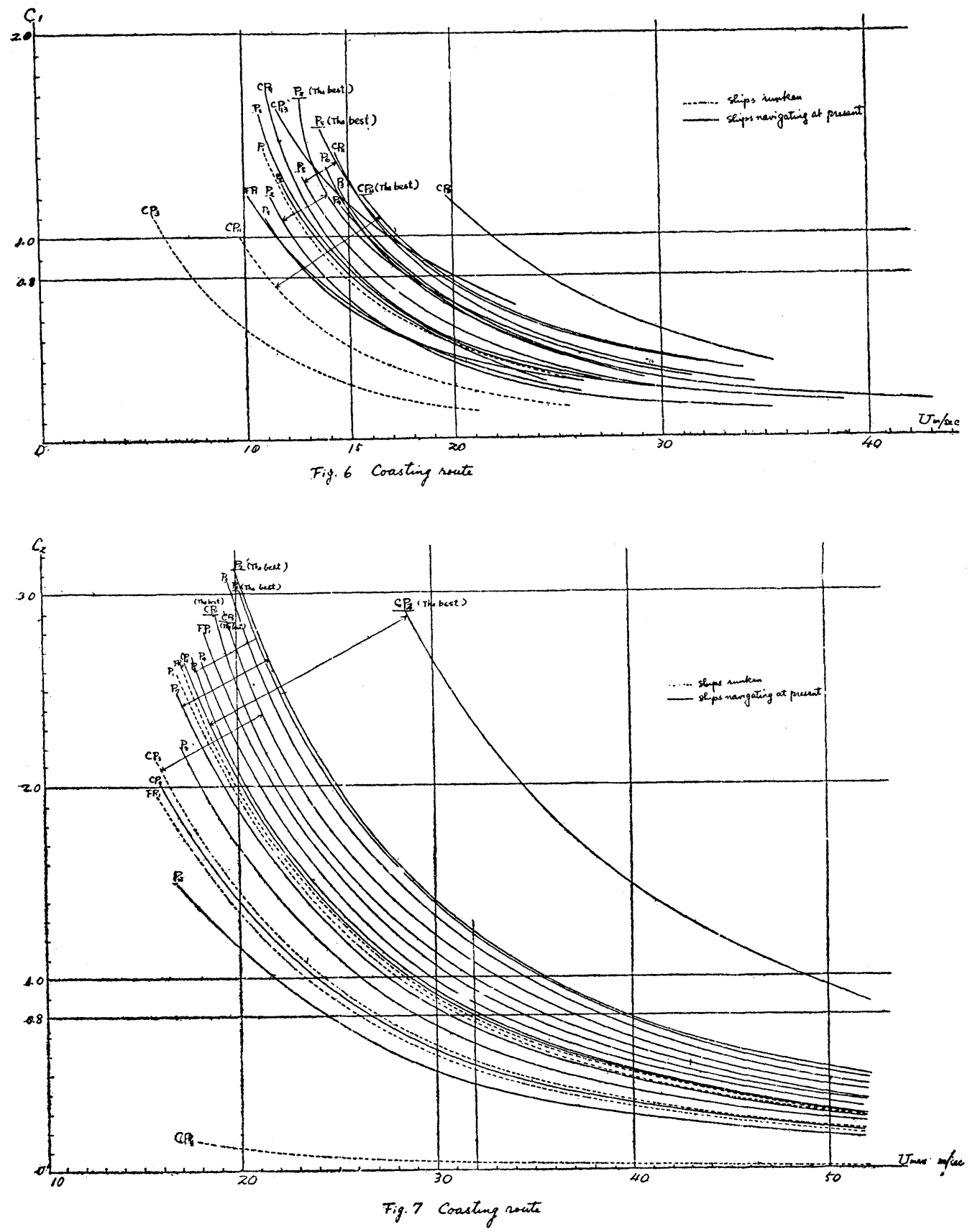

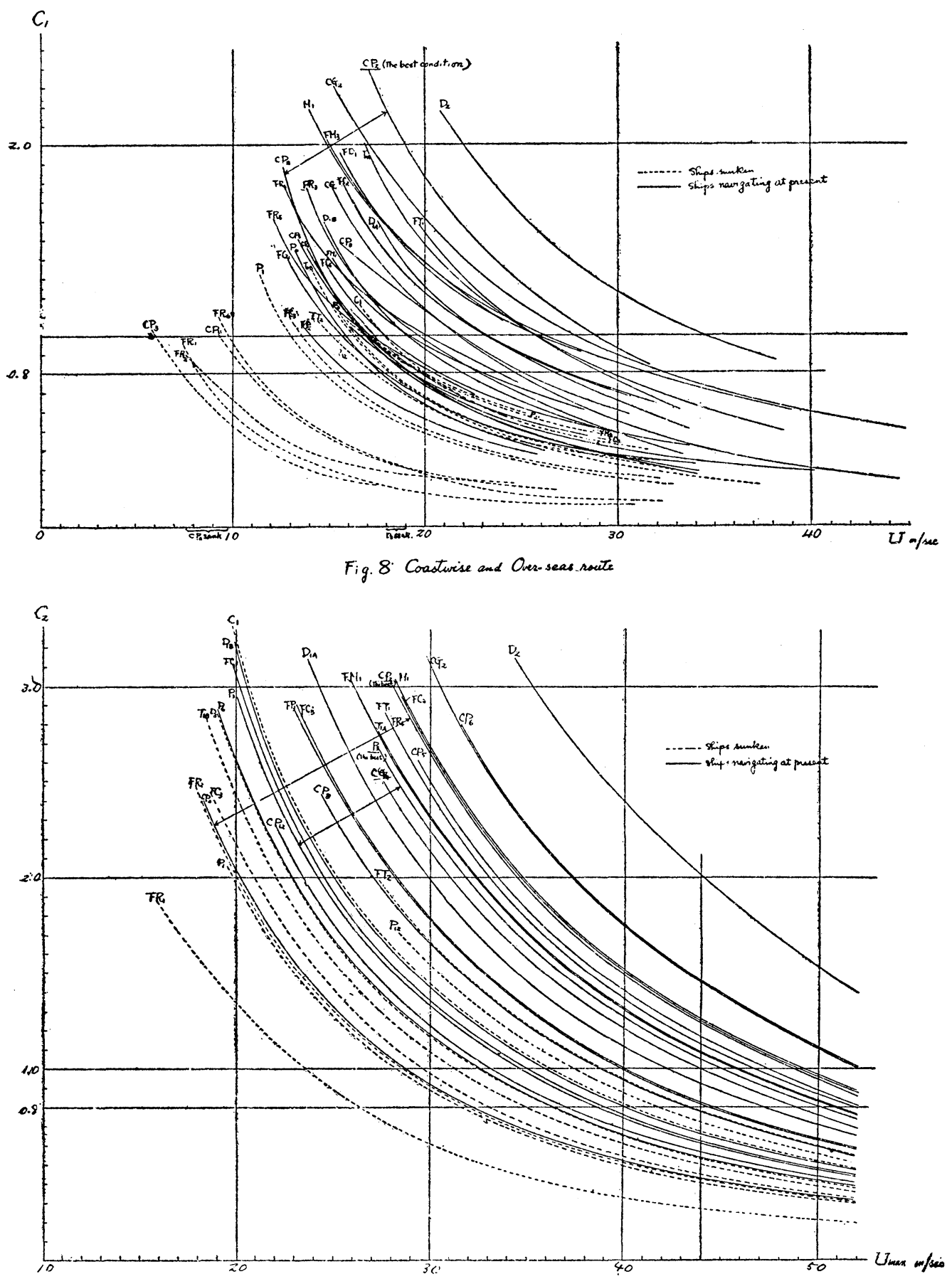

Fig. 9 Conactwise and Qverseas route

In these figures $\mathrm{P}, \mathrm{CP}$ etc. mean as follows :-
P......passenger ship
CP......cargo and passenger ship
C.......cargo ship
CG......coast guard ship
D......destroyer
T $\cdots \cdot \cdot$ torpedo boat 


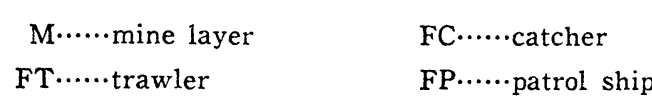

FR......small fishing boat (Tegurisen)

FM...... fishing boat (Katsuo maguro sen)

Suffix $1,2, \cdots \cdots$ No. of ships

Suffix B...... before rebuild Suffix A.......after rebuild

In the above calculations we adopted

$N=0.02$ (when ships with bilge keels)

$\gamma=0.8$ (mean value of $\gamma$ showed in Fig. 10, OG being the height of centre of gravity above water line)

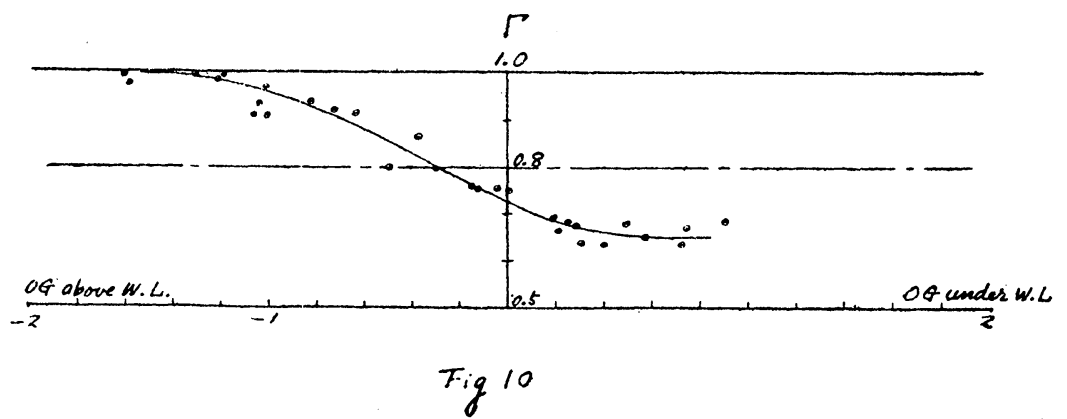

announcement, by which the captain determines her departure or her refuge, is not always so exact as we must consider the boundary layer effect. So we will neglect it.

On the other hand from the observations of ocean wind it is convenient to divide the ships into 2 groups, namely the 1st kind and the 2nd kind. As a rule the 1st kind of ships do not leave port when the warning is issued, but sometimes meet with fronts and lows unavoidably and even in this case they must be safe. By the same authors' separate paper, steady wind velocity met by suck kind of ships is fouud to be $15 \mathrm{~m} / \mathrm{sec}$ and maximum wind velocity be $32 \mathrm{~m} / \mathrm{sec}$. For the 2nd kind of ships which meet with typhoons, steady wind velocity is found to be $20 \mathrm{~m} / \mathrm{sec}$ and maximum wind velocity be $44 \mathrm{~m} / \mathrm{sec}$.

Taking these facts into considerations, and from Fig. 6, 7, 8 and 9 we shall see that the 1st kind of ships corresponds to the coasting route ships and the 2nd kind corresponds to the coastwise and over sea ships and we can take the critical values of $C_{1}$ and $C_{2}$ as 0.8 for both cases.

That is, these ships will be safe, if

$C_{1}>0.8$ when $U=15 \mathrm{~m} / \mathrm{sec}$ for coasting route

$C_{1}>0.8$ when $U:=20 \mathrm{~m} / \mathrm{sec}$ for coastwise and overseas route

and

$$
\begin{aligned}
& C_{2}>0.8 \text { when } U_{\max }=32 \mathrm{~m} / \mathrm{sec} \text { for coasting route } \\
& C_{2}>0.8 \text { when } U_{\max }=44 \mathrm{~m} / \mathrm{sec} \text { for coastwise and overseas routes. }
\end{aligned}
$$

\section{Conclusion}

For the safety of ships, two values $C_{1}, C_{2}$ namely

$$
\begin{aligned}
& C_{1}=\frac{S_{d}}{D_{w}\left(2 \theta_{r}+\theta_{0}\right)+\cdot \frac{m_{x}}{2} \theta_{0}^{2} .}=\frac{S_{d}}{\lambda U^{2}\left(2 \theta_{r}+\theta_{0}\right)+\frac{m_{x}}{2}-\theta_{0}^{2}} \\
& C_{2}=\frac{S_{d}}{\left(D_{w}+D_{w^{\prime}}\right) \theta_{r}}=\frac{S_{d}}{\lambda U^{2} \max \theta_{r}}
\end{aligned}
$$

are searched and they must be above 0.8 , where ships are divided into coasting route ships and 
coastwise and overseas route ships and the values of $U$ and $U_{\max }$ are as follows :

\begin{tabular}{c|c|c}
\hline & coasting route & coastwise and overseas route \\
\hline$U$ & $15 \mathrm{~m} / \mathrm{sec}$ & $20 \mathrm{~m} / \mathrm{sec}$ \\
\hline$U_{\max }$ & $32 \mathrm{~m} / \mathrm{sec}$ & $44 \mathrm{~m} / \mathrm{sec}$ \\
\hline
\end{tabular}

Finally, this research was intended as one of the works of the committee, provided in the Board of Transportation, to improve the regulations on the safety of ships.

We wish to express our thanks to the Chief Inspector Mr. M. Mizushina and his co-workers, and the memers of the committee for their varions helps.

(At the Department of Naval Architecture, Faculty of Engineering, Kyüshu University.) 